\title{
A Patient with Malignant Melanoma Diagnosed with Gastrointestinal Bleeding: Case Report
}

\section{Tahir Buran}

Celal Bayar University: Manisa Celal Bayar Universitesi

Burak Ceber ( $\boldsymbol{\sim}$ burakceber2@gmail.com )

Manisa Celal Bayar University: Manisa Celal Bayar Universitesi https://orcid.org/0000-0002-7953-5395

\section{Büşra Nur Ceber}

Manisa Celal Bayar University: Manisa Celal Bayar Universitesi

\section{Semin Ayhan}

Celal Bayar University: Manisa Celal Bayar Universitesi

\section{Research Article}

Keywords: Gastrointestinal bleeding, Cancer, Malignant Melanoma, Metastasis

Posted Date: June 18th, 2021

DOI: https://doi.org/10.21203/rs.3.rs-566265/v1

License: (c) (i) This work is licensed under a Creative Commons Attribution 4.0 International License. Read Full License 


\section{Abstract}

Malignant melanoma is a very aggressive type of cancer and some of patients have distant metastasis at presentation. Gastrointestinal system metastases are common and generally asymptomatic. The disease is rarely diagnosed only by gastrointestinal symptoms. Our case was diagnosed with malignant melanoma after upper gastrointestinal bleeding, characteristic lesions for malignant melanoma were seen by gastrocopy. The diagnosis was confirmed by biopsy.

\section{Introduction}

Malignant melanoma is one of the most aggressive and extremely malignant skin tumors with continuously increasing incidence (1). Gastrointestinal system metastases happen very frequently and most of them are asymptomatic (2). Gastrointestinal system metastases are observed at a rate of $60 \%$ in the autopsy series of patients with malignant melanoma (3). Abdominal pain, anemia and rarely melena are noted in patients with symptomatic gastrointestinal metastases (4). Here, we present a case diagnosed with malignant melanoma and consequently admitted with abdominal pain and melena

\section{Case}

A 75-year-old female patient presented to the gastroenterology outpatient clinic with symptoms of abdominal pain and melena. She had no history of a known co-morbidity and had a history of a nevus excision on the left side of her face 2 years ago, the pathology of which was considered to be intradermal nevus. Her hemoglobin level at baseline was $10.5 \mathrm{~g} / \mathrm{dl}$, hematocrit was $32.7 \%$, platelet count was $205 \mathrm{x}$ $10^{3} \mu \mathrm{L}$, urea was $35 \mathrm{mg} / \mathrm{dl}$, creatin was $1 \mathrm{mg} / \mathrm{dl}$, alanine aminotransferase (ALT) was $18 \mathrm{U} / \mathrm{L}$, aspartate transaminase (AST) was $27 \mathrm{U} / \mathrm{L}$, alkaline phosphatase (ALP) was $218 \mathrm{U} / \mathrm{L}$, lactate dehydrogenase (LDH) was $746 \mathrm{U} / \mathrm{L}$. The patient underwent endoscopy and colonoscopy during the same session. Diffuse ulcers and black pigmented lesions were detected in the stomach and duodenum during the endoscopy (Figs. 1,2). Biopsies were performed on the lesions. Biopsy specimens revealed tumoral cells especially diffuse in lamina propria, with brown-black pigment accumulation in the cytoplasm, and large vesicular nuclei with marked atypia. Tumor cells were positive for S100, HMB45 and Melan A (Figs. 3,4). The present findings were suggestive of duodenal and gastric metastases of malignant melanoma. The patient underwent colonoscopy and normal colonoscopic findings were observed. The patient was referred to the oncology clinic for the investigation of the primary tumor and planning the treatment.

\section{Discussion}

Malignant melanomas are malignant tumors arising from the skin cells called melanocytes (5). Its incidence is $3.4 \%$ among all cancers (6), and its prognosis is generally poor. Five-year survival rate of Stage 4 malignant melanoma patients was found to be only $14 \%$ (7). 
Excisional biopsy is still the golden standard for diagnosis (8). Presence of various morphologic variants of malignant melanoma makes pathologic diagnosis extremely difficult (9), and accurate pathologic diagnosis is important for early diagnosis and treatment.

Malignant melanoma can metastasize to all the organs but it is especially known to metastasize to the gastrointestinal system frequently (10). In the gastrointestinal system, it metastasizes most frequently to the small intestines, large intestines and the anorectal area. Gastric metastasis is known to be very rare (11). However, there were metastases to the stomach and duodenum in our case.

Gastrointestinal melanomas are frequently characterized with non-specific symptoms and signs like abdominal pain, nausea, dysphagia, upper and lower GIS bleeding and melena (12). Abdominal pain, anemia and melena were reported in our case.

Endoscopic evaluation has an important place in the diagnosis of gastrointestinal system melanoma. Black pigmented lesions, submucosal nodules, ulcerated lesions and masses with polypoid structure can be detected with endoscopy. Bull's eye appearance in the lesion is characteristic in barium analyses (13). In our case, numerous black pigmented nodular lesions and necrotic ulcers were detected in endoscopic examination.

\section{Conclusion}

Malignant melanoma is an aggressive tumor which can rapidly metastasize. Therefore, early diagnosis and treatment are important. If non-specific gastrointestinal symptoms and signs ocur in diagnosed patients, it should be kept in mind that it could be a GIS metastasis and endoscopic evaluation should be considered.

\section{Declarations}

Funding: Not applicable

Conflicts of interest/Competing interests: there is no conflict of interest.

Availability of data and material: All data are available in the archive of "Manisa celal bayar university faculty of medicine".

Code availability: Not applicable

Ethics approval: Ethical approval was obtained from the patient.

Consent to participate: Approved to participate.

Consent for publication: Approved to publication. 


\section{References}

1. Situm M, Buljan M, Kolić M, Vučić M. Melanoma-clinical, dermatoscopical, and histopathological morphological characteristics. Acta Dermatovenerol Croat. 2014;22(1):1-12. PMID: 24813835.

2. Falk V, Zepeda-Gomez S, Sultanian R, Kohansal-Vajargah A. Acute upper gastrointestinal bleeding in a patient with malignant melanoma. BMJ Case Rep. 2018 Jul 11;2018:bcr2018225869. doi: 10.1136/bcr-2018-225869. PMID: 30002219; PMCID: PMC6047700.

3. Genova P, et al. Gastric and Rectal Metastases from Malignant Melanoma Presenting with Hypochromic Anemia and Treated with Immunotherapy. Case reports in oncological medicine. 2017;2017:2079068. doi:10.1155/2017/2079068.

4. Sundersingh S, Majhi U, Chandrasekar SK, Seshadri RA, Dakshinamurthy SK, Narayanaswamy K. Metastatic malignant melanoma of the small bowel-report of two cases. J Gastrointest Cancer. 2012 Jun;43(2):332-5. doi: 10.1007/s12029-010-9180-x. PMID: 20607448.

5. Kozovska Z, Gabrisova V, Kucerova L. Malignant melanoma: diagnosis, treatment and cancer stem cells. Neoplasma. 2016;63(4):510-7. doi: 10.4149/neo_2016_403. PMID: 27268913.

6. GLOBOCAN 2020, Global Cancer Observatory 2020.

7. Alvarado-Cabrero I, Estévez-Castro R, Valencia-Cedillo R. Metástasis de melanoma al tracto gastrointestinal. Reporte de tres casos [Metastasis of melanoma to the gastrointestinal tract. Report of three cases]. Rev Med Inst Mex Seguro Soc. 2019 Apr 1;57(1):42-47. Spanish. PMID: 31071254.

8. Pavri SN, Clune J, Ariyan S, Narayan D. Malignant Melanoma: Beyond the Basics. Plast Reconstr Surg. 2016 Aug;138(2):330e-340e. doi: 10.1097/PRS.0000000000002367. PMID: 27465194.

9. Brenn T. Histologisches Spektrum des malignen Melanoms [Histological spectrum of malignant melanoma]. Pathologe. 2015 Feb;36(1):53-61. German. doi: 10.1007/s00292-014-2001-4. PMID: 25589353.

10. Liang KV, Sanderson SO, Nowakowski GS, Arora AS. Metastatic malignant melanoma of the gastrointestinal tract. Mayo Clin Proc. 2006 Apr;81(4):511-6. doi: 10.4065/81.4.511. PMID: 16610571.

11. El-Sourani N, Troja A, Raab HR, Antolovic D. Gastric Metastasis of Malignant Melanoma: Report of a Case and Review of Available Literature. Viszeralmedizin. 2014 Aug;30(4):273-5. doi:10.1159/000364814. PMID: 26288600; PMCID: PMC4513808.

12. Mikkelsen LH, Larsen AC, von Buchwald C, Drzewiecki KT, Prause JU, Heegaard S. Mucosal malignant melanoma - a clinical, oncological, pathological and genetic survey. APMIS. 2016 Jun;124(6):475-86. doi:10.1111/apm.12529. Epub 2016 Mar 22. PMID: 27004972.

13. Kotteas EA, Adamopoulos A, Drogitis PD, Zalonis A, Giannopoulos KV, Karapanagiotou EM, Saif MW, Syrigos KN. Gastrointestinal bleeding as initial presentation of melanoma of unknown primary origin: report of a case and review of the literature. In Vivo. 2009 May-Jun;23(3):487-9. PMID: 19454519. 


\section{Figures}

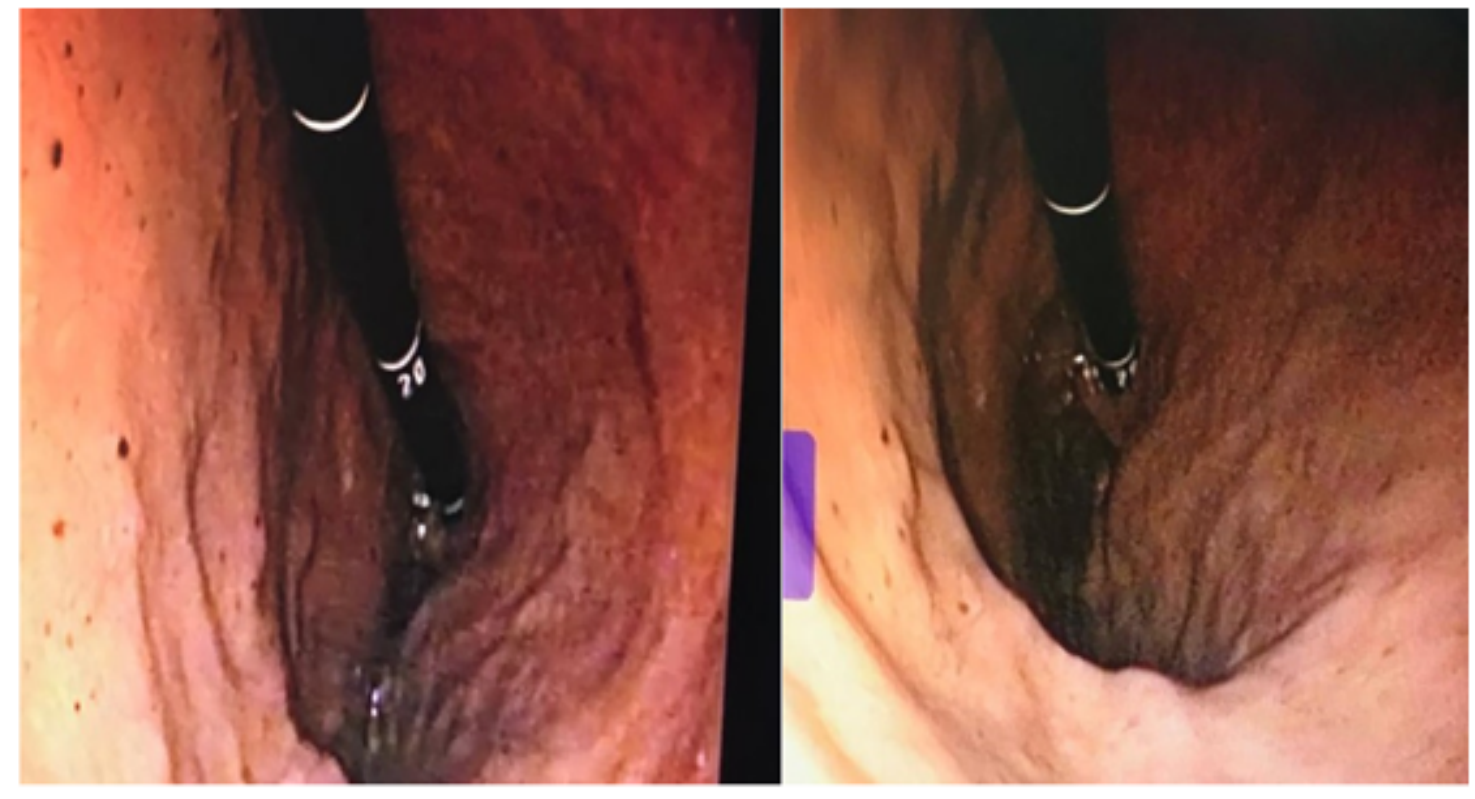

\section{Figure 1}

Malignant melanoma metastasis, black pigmentented lesions.

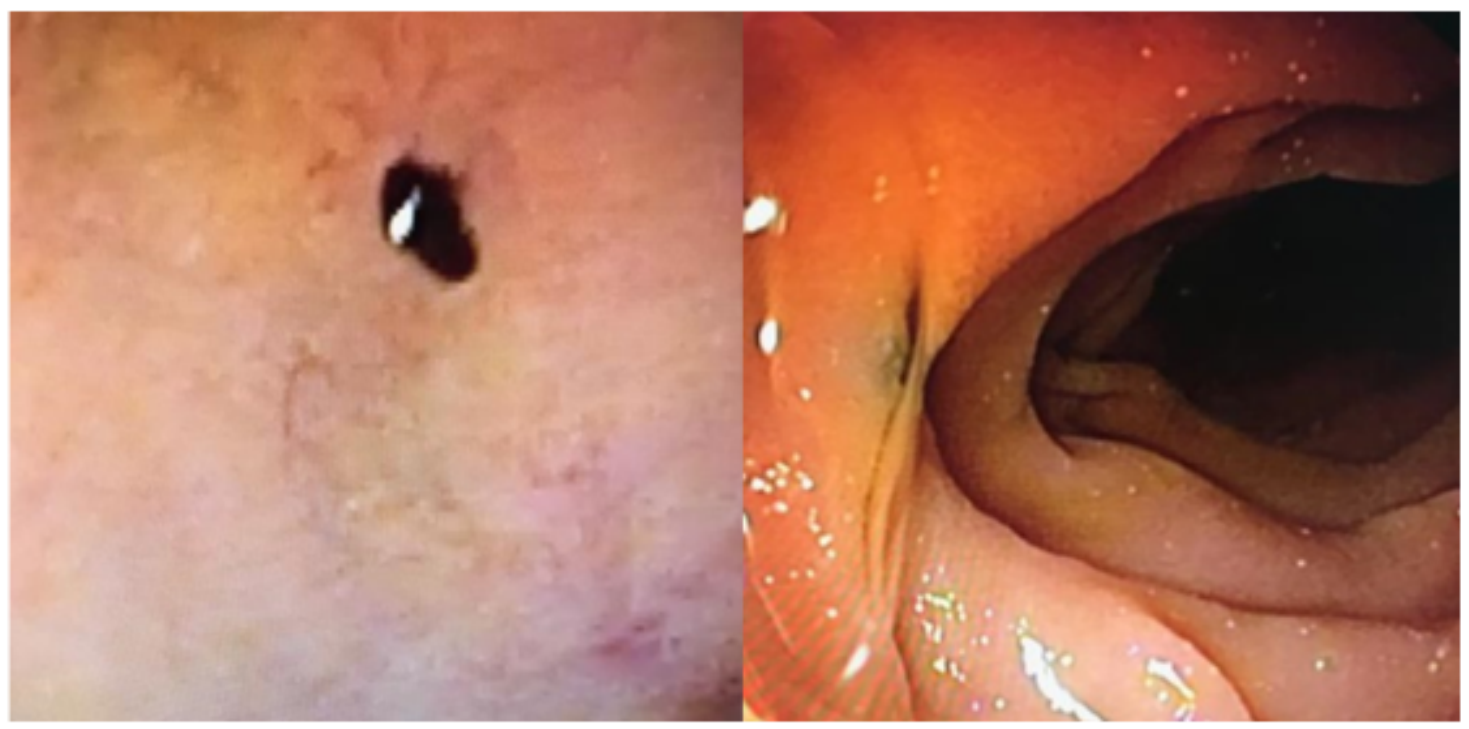

Figure 2

Ulcerated lesions containing black pigmented areas, malignant melanoma metastasis. 


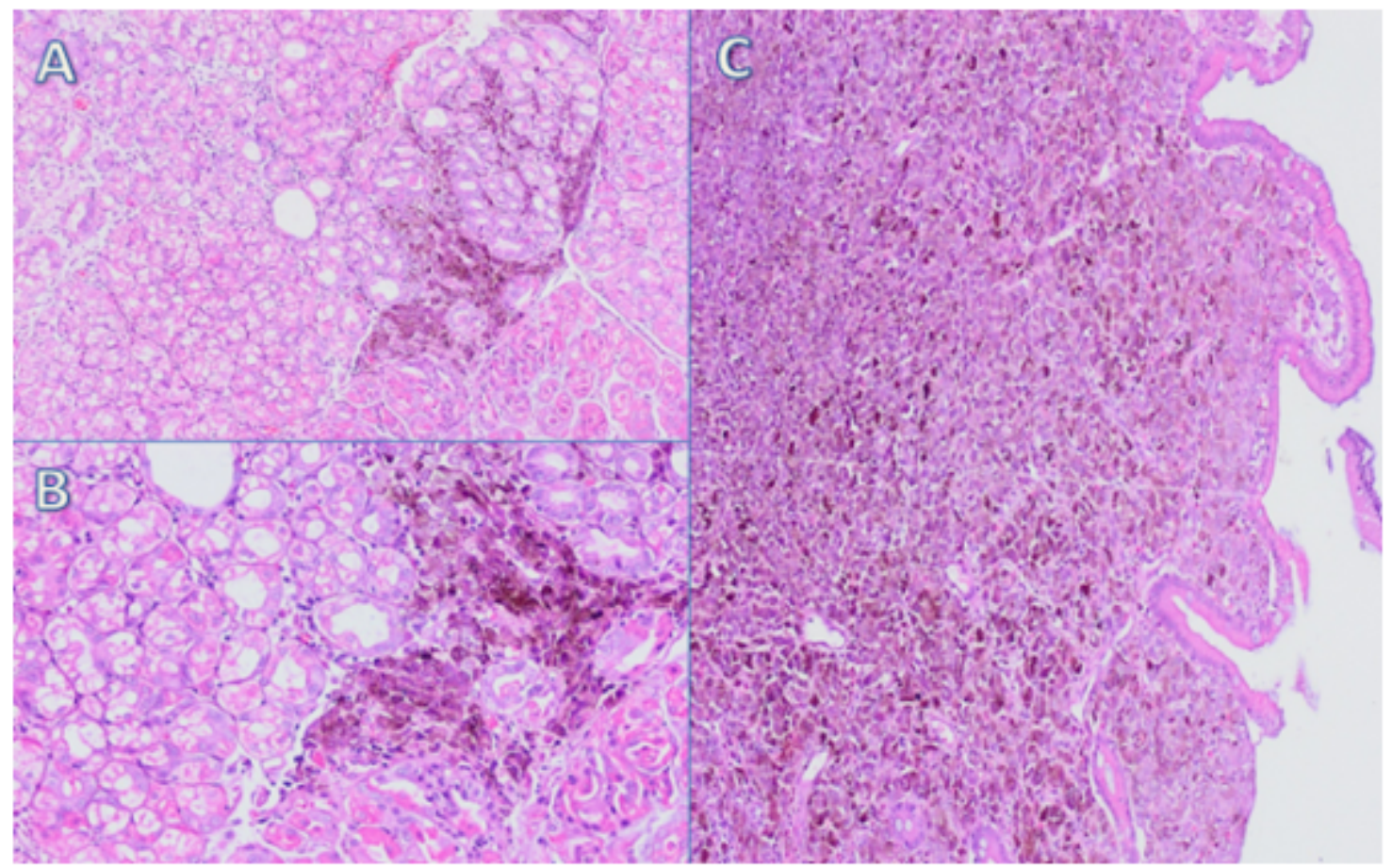

Figure 3

A: Gastric corpus, 10x magnification, tumor cells stained with hemotoxylene eosinophil, B: Gastric corpus, 20x magnification, tumor cells stained with hemotoxylene eosinophil, C: Duodenum, 10x magnification, tumor cells stained with hemotoxylene eosinophil

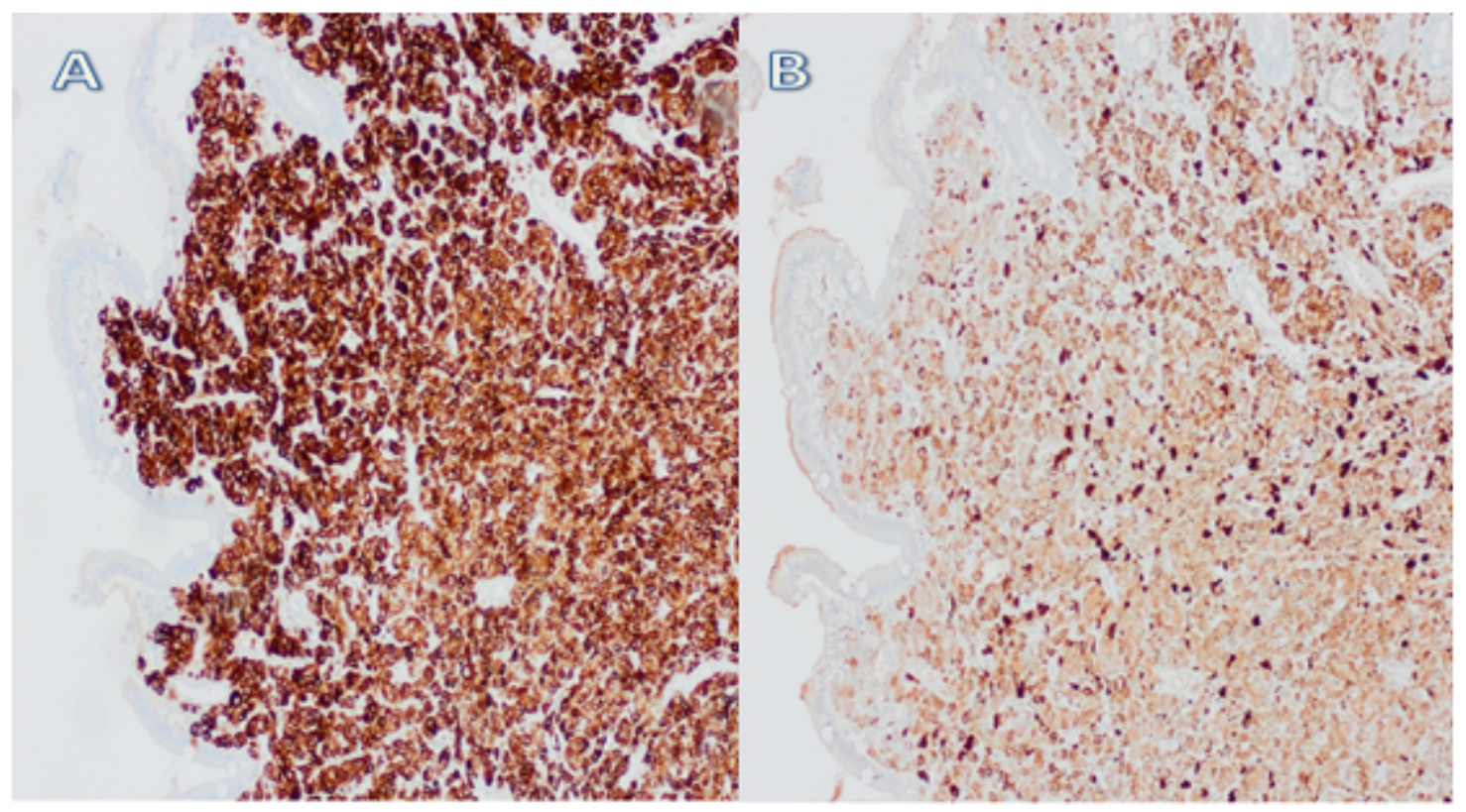

Figure 4 
A:Duedonum 10x magnification, positive staining with HMB 45 in tumor cells, B: Duodenum 10x magnification, positive staining with S-100 in tumor cells 